\title{
Democracy, Authoritarianism, and Policy Punctuations
}

Bryan D. Jones, Derek A. Epp and Frank R. Baumgartner

\section{OpenEdition}

1 Journals

Electronic version

URL: http://journals.openedition.org/irpp/318

DOI: $10.4000 /$ irpp. 318

ISSN: 2706-6274

Publisher

International Public Policy Association

\section{Printed version}

Date of publication: 17 June 2019

Number of pages: 7-26

ISSN: 2679-3873

\section{Electronic reference}

Bryan D. Jones, Derek A. Epp and Frank R. Baumgartner, « Democracy, Authoritarianism, and Policy Punctuations », International Review of Public Policy [Online], 1:1 | 2019, Online since 17 June 2019, connection on 10 December 2020. URL : http://journals.openedition.org/irpp/318 ; DOI : https:// doi.org/10.4000/irpp.318

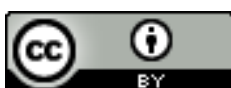

International Review of Public Policy is licensed under a Creative Commons Attribution 4.0 International. 


\section{Democracy, Authoritarianism, and Policy Punctuations}

\section{Bryan D. Jones}

University of Texas at Austin (USA)

\section{Derek A. Epp}

University of Texas at Austin (USA)

\section{Frank R. Baumgartner}

University of North Carolina at Chapel Hill (USA)

\section{Abstract}

Do democracies perform better than more autocratic political systems? Most existing literature focuses on single issues, such as maintaining the peace, avoiding famines, or promoting stable economic growth. The key to policy success for all these and other issues is adaptive policymaking in complex, dynamic environments. Relying on theory and empirical tests from policy process studies, we focus on extreme policy punctuations as indicators of maladaptive policymaking. We conceive of a continuum from the most open democracies to the most closed authoritarian systems, with intermediate forms of less open democracies, hybrid regimes, and less closed authoritarian systems. Based on a review of the existing literature, we extract four factors that seem to affect maladaptive and hence more punctuated policymaking: friction imposed by formal rules and informal norms on the policymaking process, the absence of incentives to address problems, centralization in policymaking, and lack of diversity in channels of information. Many of these factors cluster, so it is difficult to discern their specific effects, but our approach allows a start at doing so.

\section{Keywords}

policy punctuations, democracy, authoritarianism, public budgets 
Democracies are lauded both for their intrinsic value and because they seem to perform better than autocratic regimes on a number of key measures, at least over long periods of time. Proponents of democratic rule claim they are better at providing adaptive policies through mechanisms of openness and compromise. On the other hand, authoritarian regimes are often touted as providing stability and order in the face of the chaos and unpredictability of open democracies.

Economist Amartya Sen argues that democracies do not suffer from famines. He first noted that famines were simple to solve if governments had the will (Sen 1981). He later realized that famines were common in colonial and authoritarian systems, but not democratic ones. As he put it in a 2015 interview (Ebersole 2015), "If the government is vulnerable to public opinion, then famines are a dreadfully bad thing to have. You can't win many elections after a famine.”

Noting that both poverty and food shortages, even severe shortages, were common in developing democracies, Sen went on to assert that they did not develop into full-blown famines as they could do in authoritarian regimes. In discussing the Chinese famine of 1958-61, he suggested another connection to that disaster. "While the famine was going on, there was also a starving of information. This is an additional factor, the informational connection as opposed to the political incentive connection" (Ebersole 2015). Basically, the Chinese government suppressed the flow of information to cover up its failure, and ended up fooling itself into thinking more rice was available than there was. While Sen was bullish about democracy's ability to prevent famines, he was less certain about its abilities to address hunger and poverty (Dreze and Sen 1989; Sen 1981).

These observations and others like them are important because they focus on the performance of democracies rather than their intrinsic values. Yet they limit themselves to one problem at a time: are democracies better at maintaining the general peace (Reiter 2017)? Are they more effective at relieving food shortages before they become famines? Are they better at fostering economic growth (Helliwell 1994)? More generally, the issue may be stated thus: Are democracies more responsive to problems than non-democratic systems? Since problems are themselves dynamic, do democracies prove more adaptive as situations change? And how do we measure that adaptation?

Buena de Mesquita and his colleagues (2003) provide a general answer: the incentives for better policymaking are related to the size of the minimum winning coalition that chooses the governing coalition. This mechanism is distinct from the concept of democracy, although the two overlap. It also sets the issue of policy performance into a broader frame, hence avoiding the issue-by-issue approach to performance. It also treats the size of what they call the selectorate as a continuum, opening the possibility that democracies themselves vary in their incentives to produce adaptive public policies, as do dictatorships, based on the sizes of their respective selectorates. The authors claim that other aspects of democracies are not related to policies, but Clarke and Stone (2008) dispute this on methodological grounds. Additionally, the measures used by Bueno de Mesquita and his colleagues do not incorporate the assessments of adaptive policymaking that we advocate below.

Governments are mixtures of structures and norms, and dividing them into democratic versus authoritarian ignores the possibility that some facets of governments may lead to better adaptive problem-solving whereas others may not. Do some characteristics of democracies lead to more adaptive policymaking than other forms? While we applaud Bueno de Mesquita and his colleagues for conceiving the problem as a continuous one, we disagree with them in viewing these systems as more complex than they suggest. We also set adaptive policymaking as the 
key measure of policy performance. As we discuss below, we assess adaptive policymaking as the ability to avoid overly large and erratic shifts in policy commitments.

Scholars now distinguish a class of political systems that "feature key procedural characteristics of democracy, such as regular elections, while they simultaneously display attributes associated with authoritarian regimes, from the repression of the free press to infringements of civil rights" (Sebok 2019: 1). While these systems seem to rely on large selectorates, they still fall short in adaptive policymaking. Sebok $(2019 ; 1)$ terms these "hybrid regimes" and hypothesizes that they are more erratic in their policymaking than democratic regimes, but less so than fully authoritarian regimes. Sebok continues, "Policy emphases shift from one to the other in more dramatic fashion in hybrid regimes because they follow patterns of poll-governed populist decision-making rather than the gradual shifts periodically interrupted by elections that characterize agenda-setting in democracies". Do hybrid regimes perform better than full autocracies but less well than democracies?

This suggests that we may view a continuum between fully open democratic systems and completely closed autocratic ones, distinguished by the extent of control by central authorities built into the system. These gradations should be associated with more adaptive policymaking. In addition, some facets of regimes may be more associated with problem-solving than others. In this approach, the size of the selectorate is only one element in adaptive policymaking.

It is critical to distinguish between adaptive policies, which shift as challenges in environment change, and policy stability, which can be maladaptive by being overly rigid in the face of dynamic environments. Fully rigid policies in a highly-controlled political system may provide unchanging policies over long periods of time, but they are generally not responsive to the changing nature of the policy environment. In other words, they are less adaptive systems. Such systems may well be subject to more massive punctuations as they fail to detect and adjust to a gathering storm. Chinese real estate developer Chen Tianyong captured the essence of this process when he claimed that China was "like a giant ship heading to the precipice. Without fundamental changes, it's inevitable that the ship will be wrecked and the passengers will die" (Liu 2019).

Here we address the issue of democratic performance through the lenses of policy process approaches that conceive of policymaking as invariably disjointed and episodic rather than continuous and incremental. Systems vary in their susceptibility to more or less intense policy punctuations. The policy literature indicates that more intense punctuations are associated with long periods of unchanging policies, so that strong stability and intense punctuations are paradoxically causally related.

The general punctuation thesis postulates that political systems are subject to multiple streams of information on problems that could require addressing, yet they are also subject to a great deal of resistance to acting on those problems (Jones and Baumgartner 2012). The information is always uncertain and ambiguous, and hence seldom clear enough to make the appropriate action obvious. So there is always a delay in acting, leading to a tendency to allow problems to fester until they cross a threshold of criticality (Jones and Baumgartner 2005). A politics of "alarmed discovery" often follows (Downs 1972). Limits on attention are a major impediment to responding to information in all systems, but this is intensified when information is suppressed. Other forms of resistance exist, including the set of decision rules that allow veto players to stymie such action and ideological rigidities that interfere with the recognition of and response to problems (Tsebelis 1995; Jones, Sulkin, and Larsen 2003). 
The tension between the demands for action generated by flows of information and the resistance to them leads to a stick-slip dynamics, the same kind of process that generates earthquakes as tectonic plates stick for long periods of time (the friction) then suddenly slide rapidly along each other as pressure from the earth's core increases tension between the plates (Jones and Baumgartner 2012).

Political systems differ in their mix of mechanisms that foster friction and encourage open flows of information. Yet democracies share common characteristics, including regular elections with broad participation, free expression of opinion, and few barriers to organization to influence policies that, prima facie, would seem to lead to better problem-solving. Democracies also differ in numerous ways, from the length of experience with democracy to the forms of representation and governance mechanisms they employ. More open democracies have more robust press freedoms, more vibrant and effective pluralistic group structures, and representational systems that incorporate more residents and more faithfully transmit the policy views of those residents to policymakers. Less hierarchic and centralized policymaking systems rely less on executive-centered government and more on decentralized policy-making mechanisms. Similarly, autocracies share common characteristics that one might expect would lead to lessened problem solving abilities, including overly centralized governance structures and more limitations on the free flow of information. Yet they, too, differ in their abilities to solve problems.

Government performance can be assessed as responsiveness to problems. Obviously there are other criteria, but the failure to address festering problems is surely a major component of evaluating any political system. Yet the definition of a problem is oftentimes not clear, and different groups have different interpretations of the same set of indicators. However, it is possible to gain leverage on this difficulty by focusing on what adaptive problem-solving is not. While there are exceptions, in particular when the policymaking environment rapidly or catastrophically changes, in most cases severe policy punctuations are symptoms of maladaptive political systems. The larger the punctuation, the less efficient the system has been in addressing the associated problem in a timely manner. As a consequence, comparative measures of policy punctuations are inverse indicators of adaptive policy-making. Generally, incrementalist policies (as opposed to rigidly stable policies) are indicators of underlying adaptive policymaking.

\section{Assessing Adaptation by Policy Punctuations}

A major problem with assessing policy punctuations is judging when a policy change is large and when it is "close enough" to incremental (given that all systems are affected by some degree of friction). Policy scholars have turned to stochastic process approaches, in which they study entire frequency distributions of policy changes. For example, one can calculate percentage changes in budgetary allocations across budgetary categories within a single nation, calculate a frequency distribution, and compare that distribution to the standard Normal distribution (which would be expected in a purely incremental budgetary system).

The typical budgetary distribution is quite divergent from the Normal, usually displaying some positive skew (in which there are larger increases in budgets than decreases) and clear leptokurtosis (in which there are many very small changes and a few really large ones, but few moderate changes). Figure 1 displays a typical budget change distribution. It is aggregated first by calculating year-to-year percentage changes in each budgetary category, and then aggregating these for all countries measured (in this case, using the ten standard categories used by the 
International Monetary Fund for twenty-one countries for the period 1996-2011).

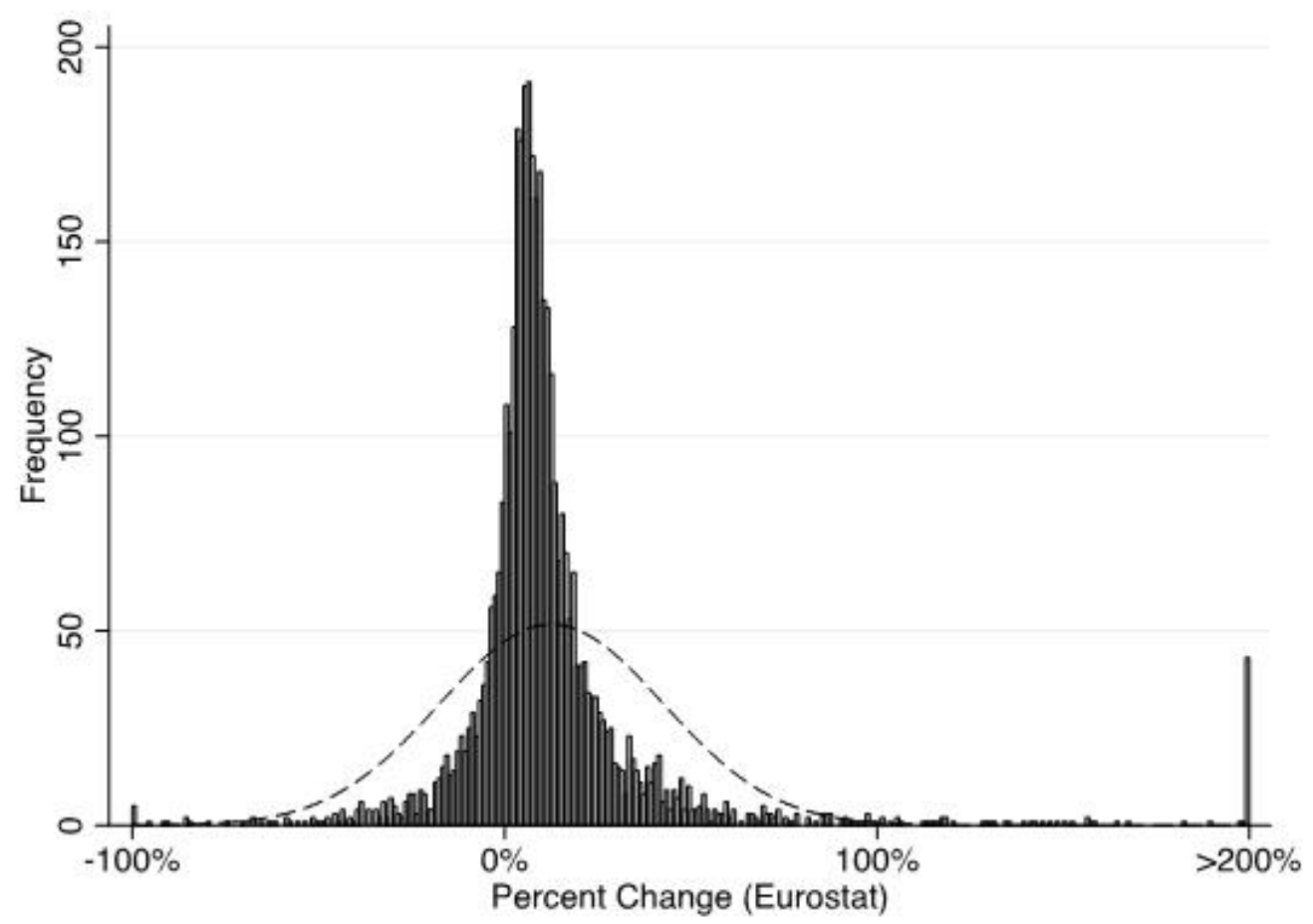

Figure 1: Inflation-adjusted budget changes for all countries.

(Source: Fagan, Jones, and Wlezien 2017)

Budget distributions can be compared with regard to the extensiveness of policy punctuations using kurtosis, or the normalized version, l-kurtosis (Bruenig and Jones (2011). This strategy can also be used for other measures of the policy process by using the policy topic structure of the Comparative Policy Agendas Project (https://www.comparativeagendas.net), calculating percentage changes in the categories across time. Positive kurtosis, or leptokurtosis, indicates high peaks and long tails (as seen in Figure 1). Long tails indicate a large number of observations with large percentage changes-which themselves indicate policy punctuations. A second approach is to estimate directly the slopes of the Pareto, or power function, distribution (Jones et. al. 2009). The Paretian distribution is characterized by very long tails; in the case of budgetary changes, this would indicate extremely large budgetary changes, whether they are positive or negative.

Scholars have examined budget distributions like this one in many different political systems, finding substantial leptokurtosis in all national-level political systems studied so far. In a comparative study of distributions of budget changes among seven developed democracies, Jones et al. (2009) found punctuated distributions in all cases examined. Fagan, Jones, and Wlezien (2017) similarly found all country-level distributions they studied to be characterized by substantial kurtosis, as was the combined distribution presented above. Positive kurtosis also characterizes sub-national governments, including U.S. states (Breunig and Koski 2006) and U.S. local governments (Jordan 2003), Indian states (Karmarkar 2016), Danish local govern- 
ments (Jones et al. 2009), and Texas school districts (Robinson 2004). Specific policy areas within single political systems seem generally to be characterized by punctuations (True 2000). Jones, Sulkin, and Larsen (2003) considered various stages of the policy process in the U.S., and Baumgartner et al. (2009) did so in three western countries; both teams found that friction increased from the input stage to the policymaking stage to the policy output stage.

The kurtosis measure calculated across countries can be deployed as a dependent variable in regression analyses. This allows investigators to study potential causes of the extensiveness of policy punctuations by associating potential causal factors with country-level budget kurtosis measures.

\section{Four Factors Leading to Policy Punctuations}

Performance differences among democracies, hybrid regimes, and autocracies may be traced to the extensiveness of maladaptive policies, which in turn is indicated by the severity of policy punctuations. We noted above that Sen pointed to both an incentive and an information linkage to the maladaptive policies in addressing famines in colonial and authoritarian regimes. We add two other factors: the friction in enabling decision-makers to respond, and the extent of centralization in a policymaking system. Hence the degree of maladaptive policymaking in addressing problems is likely to be a function of four general factors. The incentive factor focuses on the extent to which politicians face inducements or sanctions that encourage them to detect and solve problems. Information centers on whether systems are in place to process information that indicates problems; problems must be detected and defined before they are addressed. Friction involves structural impediments to problem-solving actions by policymakers. Centralization means the concentration of decision-making power at the top of governmental organization. Of course, in the real world there is considerable overlap among these factors, but conceptually they are distinct.

\section{Friction in the Policymaking Machine}

In any system there exists a great deal of friction or resistance to policy change. It takes a certain degree of mobilization to overcome such friction and produce policy action. Friction can come from institutional structures, such as separated powers in the U.S. system, or from cognitive and cultural factors, such as ideologies that rule out certain adaptive policy actions.

Friction in government is not in itself a bad thing, since it provides the necessary stability to allow individuals and organizations to rely on a stable framework within which to operate. Because all systems face multiple problems, juggling attention among them entails neglecting certain problems at the expense of addressing others (Jones and Baumgartner 2005). This implies that no political system can avoid policy discontinuities. Yet extremely high levels of friction can allow problems to fester. Policy scholars use an error accumulation approach in which neglected problems can grow, and earlier policies put in place to address those problems become more and more obsolete as potential solutions. As errors accumulate, the system requires more and more effort to solve the problem, requiring larger and larger policy punctuations in, for example, budgetary allocations. (Jones, Sulkin, and Larsen 2003; Jones and Baumgartner 2005).

The Chinese famine associated with Mao's Great Leap Forward was the worst famine in modern history, causing approximately 30 million starvation deaths. Government policies rooted in collectivization and industrialization, as well as resistance to information indicating great suffering in the countryside were responsible. Resistance to reform was powerful, and incentives 
to address the problem were weak. The extent of centralization at the top of the Communist Party hierarchy meant that flows of information up the hierarchy were ignored and lower level officials were often sanctioned for initiating them. Indeed, they offered grossly exaggerated harvest estimates to impress superiors. Government lacked the incentives to correct course, and the system suppressed the necessary information to do so.

The famine ended with policy changes that began in 1961, as the government instituted the necessary reforms. But this only occurred after extensive and needless suffering, and required huge policy changes to accomplish. This kind of enormous policy adjustment is characteristic of political systems that have weak responsiveness to information signals about the severity of problems that the system faces, cultural or ideological blinders that divert attention away from the problem, and highly centralized systems benefiting entrenched interests that incentivize the suppression of information on problems.

A second mechanism of maladaptation stems from overreaction to a recognized problem, which can develop into a policy bubble similar to those occurring in an overheated economy (Jones, Thomas and Wolfe 2014; Maor 2012, 2014). These overreactions are more likely in systems with high friction, since the lack of earlier adjustment to changing circumstances can lead to a heightened sense of panic as policymakers realize how far off the mark their positions are.

The extent of friction in a policymaking system acts as a brake on the transferal of demands and needs for policy change into policy action. No system is immune from the frictions that prevent the translation of observed problems into solutions to make those problems disappear, and indeed, many entrenched interests within democratic systems, just as in other types of systems, may operate to perpetuate such issues. While no system seems to be able to adjust smoothly to changes in their policymaking environments, some seem to experience larger (and generally less frequent) policy punctuations, while others adjust in a less punctuated (but still non-incremental) fashion. Democracies are not uniformly equipped to address problems. While we lack quantitative evidence, not all authoritarian regimes are equal in their abilities to adjust to changing circumstances as well. Understanding these variations in democratic systems, where we have considerable evidence, can lead to a better understanding of the causes of pathological policy punctuations. It is also likely that the same principles that lead to less policy disruption and more incrementalist adaptations to changing flows of information in democracies also apply to less democratic hybrid regimes and autocratic regimes.

We can state this notion as follows, which is a modification of earlier statements of the thesis (Jones and Baumgartner 2012):

General Punctuation Thesis: The higher the level of political friction to inputs, the longer the periods of stability but the larger the policy change that invariably comes as the political system adjusts to its complex environment.

The idea that high levels of resistance, or friction, lead to more extreme policy punctuations was first articulated in a study of the extent of punctuations in the policy cycle (Jones, Sulkin, and Larsen 2003; Jones and Baumgartner 2005). The idea was that it should be easier to access the policymaking process early in the policy process - that is, in the agenda-setting stagesthan in later stages - the enactment of laws or the allocation of budgets. This was found to be the case in the U.S. A later comparative study in Belgium and Denmark as well as in the U.S. found that as friction increased in the policy cycle, so did the extent of policy punctuations (Baumgartner et al. 2009). These studies assessed such things as parliamentary questions or congressional hearings as relatively low-cost or low-friction monitoring features of the system, 
then law-making features, then budgeting and other policy outputs. As the process is further along the policy process, institutional costs for adjustment are typically higher, and so, therefore, is the friction apparent in its policy outputs.

Progressive Friction Hypothesis: Friction is lower in processes associated with putting problems on the policymaking agenda than in processes related to enacting policies addressing those problems.

It may seem obvious that it is easier to discuss an issue than to achieve action on it. But there is a rich literature on agenda denial—the ability of policy-relevant elites to stop issues from getting actively discussed in a political system but get the issues through when they actively support putting them on the agenda (see Jones, 2016, for a review).

Why does friction increase as we proceed along the policy cycle? There are two reasons. One is that institutional rules make the constructing of winning coalitions more difficult in the decision stages of the process than in the agenda-setting stages. Another is that as an issue proceeds through the policy cycle, it attracts more attention and hence more opposition in a counter-mobilization effect.

A related issue is whether resistance is stronger in the early stages in some political systems than others. This is highly likely to be the case. In comparison with presidential systems, it can be harder to get an issue on the agenda in parliamentary systems, in which the majority coalition controls the policy matters that are brought to parliament for consideration, but easier to get them through once they get on the agenda. In these systems, it is likely to be more difficult to get an issue through even if it is under active consideration. In authoritarian systems, agenda control is likely to be even more stringent, making it still harder to get decision-makers to attend to festering problems.

Jones et al. (2009) calculated a summary measure of institutional friction based on four factors: bicameralism, decentralization, single-party governments, and executive dominance. They found a strong relationship between the extent of institutional friction and the kurtosis of each nation's budget change distribution. The stronger the institutional friction in democratic systems, the more likely that large budgetary changes occur at the expense of more moderate adjustments to changing circumstances. The weaker the institutional friction, the more gradual and moderate the changes. Institutional friction is linked to the smoothness or punctuated nature of the policy outputs. The higher the friction, the more punctuated the output. The lower the friction, the more efficient the system.

Other budgetary studies report similar results. Ryu (2009) finds that U.S. state-level fund restrictions result in larger budget punctuations than more flexible expenditure categories. Such seemingly simple categorical systems can add friction to a system by limiting the mechanisms that politicians can use to address emerging problems.

The initial punctuated equilibrium notion was developed to address the resistance of locked-in policy subsystems to necessary policy change (Baumgartner and Jones 1991; 1993). These decentralized systems operated out of the limelight, allowing industry-centered interest groups to have a disproportionate influence on the rule-making process. Worsham and Stores (2012) show how policy changes can be met with strong resistance in some policy subsystems at the implementing stage. They examined the resistance of the agricultural policy subsystem to addressing discrimination against African American farmers in the U.S. even after major legislation was passed, concluding that major policy regime change does not necessarily occur even after major efforts to address a problem. Thus, levels of friction can be underestimated by 
focusing on policy enactments (or even budgetary changes) alone.

Can the friction hypothesis be extended to differences between authoritarian and democratic regimes? The available evidence suggests that it can. Chan and Zhau (2016) show greater budgetary punctuations in communist authoritarian systems than in limited authoritarian or liberal democratic regimes (although the comparative reliability of data is difficult to assess in this case). They also studied differences in budgetary punctuations in Chinese provinces, finding more severe punctuations where regional administrations were more closed to inputs (assessed as labor unrest). They conclude by recognizing that opposition groups not only act as obstructionists to majority policymaking, but also as challengers to policy priorities. Hence they provide information on festering problems to governing elites. As a consequence, authoritarian systems that disempower minority coalitions are worse, both at addressing developing problems and at limiting the overreaction of "alarmed discovery" when they (belatedly) come to the attention of policymakers.

One strong research design for studies of the question of authoritarianism versus democracy focuses on examining systems shifting from authoritarianism to democracy or vice versa. Country characteristics are held constant, especially if the shift is abrupt. For budget studies, however, it is possible that budgetary categories are changed in the process, or the manner in which data is gathered or reported is altered. An exemplary study by Lam and Chan (2015) uses data coded according to the Comparative Policy Agendas protocol to compare policymaking in Hong Kong as it moved from a colonial to a postcolonial regime. Using four different measures coded from government documents (legislative deliberations, the policy address delivered by the governor [pre-1997] and the chief executive [post-1997], the budget speech delivered by the financial secretary, and annual budgetary estimates proposed by policy bureaus and departments), they found higher levels of punctuated outputs in the colonial period than afterward.

The robustness of the authoritarianism hypothesis is impressive. Baumgartner et al. (2017) examine public budgeting in Brazil, Russia, Turkey, and Malta before and after regime changes to more open, democratic forms of government. In all cases, they show that punctuations are more severe during periods of non-democracy. Epp (2018) considers annual changes in Gross Domestic Product across dozens of countries with different forms of government. Epp reasoned that because autocracies tend to exert greater central authority over their economies, they would impose governmental frictions onto economic systems. Consistent with the authoritarianism hypothesis, he finds that economic growth is more stable in countries with democratic forms of government, and gradually becomes more erratic moving along a continuum to less open regimes. Pritchett and Summers (2014) report discontinuous falls in growth rates in developing countries after rapid growth periods, and suggest that authoritarian features in China make a discontinuous decline even more likely.

In a particularly strong study, Sebok and Berki (2018) assembled a budget series for Hungary between 1868 and the present day, allowing them to examine changes in political regimes and their effects on budgetary punctuations. Dividing modern Hungarian history between 'free' (1990-2013) and 'non or partially free' (1868-1989), the researchers found more extensive budgetary punctuations in the latter period. Given recent changes in Hungary, it will be interesting to monitor budget changes because we have a firm prediction: budgetary kurtoses should increase as the period of authoritarian democracy is extended under President Orban.

Policy punctuations stem from under-addressing festering problems, and then overacting in efforts to deal with out-of-control situations. This should be worse in authoritarian systems. 
There is evidence that democracies provide more stable economic growth patterns, perhaps by adopting more appropriate macroeconomic policies (Quinn and Woolley 2001). But Quinn and Woolley's study, as well as other studies in this vein, examines the relationship between democracy and growth patterns, not between democracy and incremental adjustments in macroeconomic policies. Moreover, democracies as well as autocracies are capable of massive underappreciation of festering economic problems, as the Great Recession showed.

\section{Incentives to Solve Problems}

The second factor in explaining the severity of policy punctuations is the incentive structure political leaders have to address and subsequently enact and implement policies that alleviate those problems, thereby attenuating policy punctuations. While it is true that elections provide incentives to political leaders to address problems, it is also true that politicians face competing incentives to maintain the current policy settlement. These include such factors as electoral fundraising, interest-group pressures, and party ideologies. Nevertheless, if electoral incentives matter, then signals from the public should cause a more rapid adjustment to incoming information regarding problems, and the stronger those signals are transmitted, the higher the probability of action.

Political systems differ in the efficiency of the representation of public opinion, in the sense that some systems of representation transmit signals from the public more seamlessly than others (Soroka and Wlezien, 2010; Wlezien and Soroka 2012). Efficiency of representation is enhanced in non-federal systems (at least for central government policymaking) and attenuated where executive power is too strong. It also seems to be attenuated in systems with a plethora of political parties. Representational efficiency is also fostered where political systems have advanced mechanisms for recognizing and processing public opinion signals, allowing them to access the policymaking agenda during inter-election periods. Research suggests that proportional representational systems are more efficient directly after elections but less efficient between them (Soroka and Wlezien 2015; Wlezien and Soroka 2015).

Because the thermostatic model that these studies are based on includes a strong feedback element, it implies that issues and concerns troubling the public are addressed in the process. Responsiveness to mass opinion may lead to under-addressing or overreacting to problems, but in efficient systems thermostatic responsiveness to changes in public opinion between elections should compensate for such errors in matching policymaking to opinion. Authoritarian systems tend to lack serious representational systems, whereas hybrid systems lack some key features of efficiency in representation. Hybrid systems often rely on "poll-governed populist decision-making" (Sebok 2019:1) and are likely to be less influenced by inter-election changes in popular opinion. Such hybrid systems also rely heavily on popular mobilizations centered on single issues, such as immigration, which clearly leads to a neglect of other critical issues. Hence in general we expect that problem-solving will be enhanced in representationally efficient systems. Such systems should receive feedback from the public about policy actions or inactions across all issues more efficiently. This line of reasoning leads to the following proposition:

Representational Efficiency: Policy punctuations should be more severe where representational systems are less efficient.

The efficiency of representational systems centers on the seamlessness with which public opinion is transmitted into the decision-making process. Fagan, Jones, and Wlezien (2017) address the connection between policy punctuations and representational efficiency directly, and show 
that in systems where institutional features, such as executive dominance, electoral systems, and federalism, impede that translation, policy punctuations seem to be more severe.

Political elites are generally more polarized than mass publics, and parliamentary polarization may indicate a lack of faithful translation of opinion into the policy-making process. Tsebelis (1999) demonstrates that an association between the number of veto players and their ideological distance reduces the ability to produce major laws. Similarly, Breunig (2006) shows in a comparison of budget time series between Denmark, Germany, and the United Kingdom that punctuations are more extreme where ideology is strong and the distance between the parliamentary parties is great.

The role of federalism in producing policy instability may be mixed, acting in contrary ways. It seems to impede representational efficiency in central governments in such systems, but it also offers a more diverse source of information on problems and potential solutions for them across subnational governments.

If the general notion of efficiency in representational systems is valid, then the same reasoning should extend to the progressive friction hypothesis. That is, as friction increases through the policy cycle, we should observe a waning of the effects of public opinion on policy activities. For example, it should be easier to get an item of general public concern on the policymaking agenda than to take action on it. That is exactly what Jones, Larsen, and Wilkerson (2009) found in their study of the correspondence between the public's assessment of the most important issues facing the nation and the response of government using data from the Policy Agendas Project (see also Mortensen 2009). Chaques Bonafont and Palau (2011) report similar findings from Spain. In systems that add more friction in the policymaking system, it is far easier to detect problems than to actually pass policies addressing those problems.

A similar line of thought led Bevan and Rassmussen (2017:1) to study how the structure of interest group populations "affects the process through which the public's issue priorities are translated into policy priorities". In their study of policy attention at the U.S. federal level, the authors found that the size of the interest group population had a positive effect on the link between public priorities and government action. But as institutional friction increased, the connection attenuated. If the size of the interest group activity in a policy area indicates openness in that area, then openness would seem to facilitate the efficiency of the representational system.

We may summarize this in the proposition below:

Signal Attenuation: Governments incorporate social signals such as those from public opinion early in the policy cycle, but the signal attenuates as it moves from the agendasetting stages to the decision stages of the cycle.

\section{Centralization}

One persistent claim made again and again in both democratic and authoritarian regimes is that strong central authority leads to more adaptive policy choices. And indeed at the extremes too little central power leads to a lack of adaptive policy choices. In the U.S., for example, lack of adaptation in policy choices led to the replacement of the Articles of Confederation with the current Constitution, which involves a balance between central and dispersed power. Nevertheless, oftentimes the disadvantages of central control more than offset its advantages in the problem-solving process.

Chief executives in democracies like to make a policy difference: where executive power is 
stronger relative to legislative power, they have more opportunities to do so. These powers seem to add to policy punctuations. U.S. state governments with chief executives holding stronger institutional powers experience more severe budget punctuations than those with weaker governors (Breunig and Koski 2009). Breunig and Koski (2018) explain this by noting that U.S. state governors with more formal budgetary powers try to express them by shifting the fiscal priorities of the states they lead. They show that "executives deepen large cuts and boost large increases in budgetary change", hence adding to budgetary instability. This is a consequence of both agenda-setting and decision-stage powers, particularly veto powers. In a second paper, Breunig and Koski (2012) show that the results of such executive action are not necessarily positive in the long-term. Budgetary punctuations may achieve large effects immediately, but they are less likely to sustain themselves over the longer term than more adaptive incremental adjustment.

Although it is common to see strong executives as providing policy stability, research does not seem to bear this out. The work of Breunig and Koski indicates that strong chief executives in U.S. state government adds instability to long-run state policy. Sirimaneetham (2006) shows an association in developing countries from 1970 to 1999 between presidential systems and policy instability.

Centralization: In systems of separated powers, more centralized governments experience more severe policy punctuations.

\section{Information}

Obviously, public opinion is a critical facet in the demand structure, especially where it is backed up by electoral incentives. Collective public opinion also provides critical information about problems and potential policy solutions, but it is not the only part. Information also comes from more specialized interest groups, political party activists, governmental bureaucracies, universities, and think tanks.

Baumgartner and Jones (2015) distinguish between information on the detection and definition of problems, and the search for adequate solutions. They argue that diversity in perspectives is necessary for defining problems (what they call entropic search), but that solution search is often best left to those particularly knowledgeable (expert search).

A common problem in decision-making is confirmation bias, which involves seeking out evidence that supports our preconceived understandings (Kahneman 2011; Lodge and Taber 2013). Confirmation biases are often confounded in collectivities as it becomes increasingly difficult to articulate divergent views in the face of group pressures. But the issue is broader, since the limits of information-processing through what Herbert Simon called "the bottleneck of attention" lead to misrepresentations of reality because we pick and choose what we think are the important parts. Even the combination of indicators into a single index can mislead because of omitted non-measured variables and the weighting schemes employed (Bauer 1966).

In a prescient essay in the 1960s, Kenneth Boulding (1966: 167) warned us of the collective consequences of avoiding information overload through selectivity:

There seems to be a fundamental disposition in mankind to limit [the] agenda, often quite arbitrarily... Even though there may be good reasons for limiting [the] agenda to prevent information overload, nevertheless, limiting the agenda is always costly and is sometimes very costly, and there is something about this process which prevents us from realizing how costly it is, simply because we cannot know the cost of limiting the agenda unless we widen it, which act, of course, the very process of limiting the agenda forbid. Hence what 
looks like rational decisions under limited agendas often turn out to be disastrous.

In complex situations, humans tend to focus attention on a single facet, or at least a limited number of them. While organizations can compensate for limits of attention, they can also act to channel human cognitive limitations into their decision-making processes. Such organizational canalization leads to disjointed and episodic decision-making as the failure of the existing informational frame in solving a problem becomes increasingly obvious (Jones 2001).

Existing work in several fields indicate that diversity in flows of information is critical to good decision-making. Deliberately including discordant views in decision-making processes helps avoid the confirmation bias and acts to stimulate innovation. Scott Page recommends distributed problem-solving, involving different units not directly collaborating, to promote innovation in solutions (Page 2008). Baumgartner and Jones (2015) extend this to governance mechanisms involving policy subsystems and legislative systems.

Building on this, Epp (2018) looks for policy arenas where the task of policymaking is distributed across a range of independent and diverse decision makers. One example is exchange rates. In some countries, rates are determined by trading on broadly accessible financial markets, allowing millions of investors from around the world to speculate on the value of traded currencies. But other countries take steps to ensure that their currency is valued within some narrow bandwidth, limiting decision-making to deliberation among a small political elite. Epp shows that changes in the value of freely traded currencies are almost normally distributed, implying a smooth translation of inputs into outputs, while the value of currencies undergoing price manipulations are highly punctuated. Thus, the decision-making processes through which policymaking is organized can have profound effects on the stability of policy outputs, and the degree to which different processes can incorporate diverse inputs appears to drive this relationship.

Often, the first informational problem of government is explicit secrecy and the deliberate suppression of information. In his tour de force on policy analysis, Walter Williams (1998) stresses the fundamental need for information availability and openness, both for government agencies and the groups and organizations that monitor government action. Indeed, he sees the function of making reliable information available and accessible to policymakers as the key function of policy analysts working in government.

Given that information on problems exists or can be generated, the key question for us is how political systems process that information. Information on problems must be prioritized and evaluated for relevance. In open democracies, governments can process the information, ignore it, or even suppress it. If a government processes that information, it may defer to citizens, interest groups, political partisans, and others affected by the problem, on the one hand, or more objective policy experts from government or private non-partisan organizations on the other (Baumgartner and Jones 2015). It is difficult enough to have open discussions on controversial issues in more democratic systems-witness the suppression of discussion of climate change in the U.S. Congress. But it is far worse in non-democratic systems. Recall our discussion of famine during China's Great Leap Forward, when purposefully misleading information was delivered to policymakers for fear of reprisals.

The suppression of issues does not usually make them irrelevant. The error accumulation model implies that the more information is suppressed regarding an issue, the more drastic the policy action that must be taken. Add to that the phase of decision that Downs (1972) called "alarmed discovery" and its attendant sense of urgency and even crisis, there is a heightened 
danger of overreaction and the development of policy bubbles, increasing the size of the policy response as more adaptive adjustments are deferred or suppressed (Jones, Thomas, and Wolfe (2014; Maor 2012; 2014).

Given the above, we offer the following proposition:

Information diversity: The more open the governance system in a democratic system to flows of information bearing on problems, and the less centralized and hierarchical the policymaking system for acting on that information, the less punctuated will its policy outputs be.

While the argument is persuasive given existing work in diverse fields, direct evidence on this proposition is limited. Boswell (2012: 367), substantiating her claims with an examination of immigration policies in the United Kingdom, examined two propositions concerning information flows and policymaking.

First, different policy areas are associated with distinct practices in monitoring policy problems: some produce abundant, ongoing, and reliable information, while others yield scarce, sporadic, and/or unreliable data. Second, these variations in information supply are likely to influence political attention, with information-rich areas associated with a more proportionate distribution of attention, and information-poor areas yielding punctuated attention.

The systematic monitoring of information relevant to a policy area leads to more seamless information flows, and less punctuated patterns of policy outputs. Conversely, the absence of or suppression of information, causing it to emerge more sporadically often through media stories, is likely to lead to error accumulation in addressing festering problems and larger policy punctuations.

It is highly likely that variation in press freedoms across nations is related to the extensiveness of policy punctuations. Unfortunately, we have no studies of variations in the nature of a nation's press freedoms and the extent of punctuations, but there are a number of clues. For example, Pal (2011) studied 98 countries from 1995 to 2005, finding that a media which is freer of government influence was associated with lower levels of social and political insatiability, measured through several different indicators.

Media attention can also cause increased attention and opposition to policies, which can impede enactment. In a careful study of the U.S. Congress, Wolfe (2012: 109) shows quantitatively that "Controlling for other factors, the speed of bill passage slows down as media attention increases". This implies that media attention can add friction to the policy process, abetting the accumulation of error. On the other hand, it can serve to winnow poorly designed policies, perhaps limiting the development of "policy bubbles" of overreaction.

These connections seem to be intensified in authoritarian systems. Chan and Zhau (2016) postulate an "authoritarian information disadvantage". This disadvantage stems from issue suppression through a variety of mechanisms, including limitations on press freedoms and government secrecy and disinformation. The authors show inverse relationships between budgetary punctuations across Chinese provinces and indirect measures of openness (frequency of labor disputes).

Information availability and its use are increased where there are more institutional supports for it. For example, in parliamentary systems question periods can serve as a mechanism for raising and defining problems that governing coalitions may want to suppress. In effect, they confer some agenda influence on minorities, making the system more open (Green-Pedersen 
and Mortensen 2010). Far from being "cheap talk", they can serve as a device to expand political conflict by attracting media coverage (Vliegenthart and Walgrave 2011; Seeberg 2013;). Moreover, even within the family of democratic political systems, more openness in information processing may be associated with smoother adjustments and hence fewer policy punctuations. In a study of reforms to increase openness in the U.S. Congress in the 1970s, Robinson and Caver (2006) found reduced budgetary punctuations after the reforms were put in place. Given the shifts toward more centralized party control in Congress after 1995, it would be instructive to see if policy punctuations have increased since then.

The downside of open information provision is the risk of information overload. In his study of U.S. state-level budgeting, Ryu (2009) reports that both institutional friction and information oversupply lead to increases in both budget stability and policy punctuations, as expected. If information is assembled in a more efficient manner, it has the effect of lowering punctuations because it allows more precise policy solutions to emerging problems. This suggests that sound policy analysis and bureaucratic expertise would lead to attenuated punctuations. Robinson (2004) found exactly that in his study of local school districts in Texas. Moreover, in these local school districts, bureaucratic centralization leads to more punctuated policy outputs-that is, centralized school bureaucracies experience more budget instability than do more pluralistic bureaucracies. In general, the available evidence indicates that more pluralistic forms of information supply lead to fewer extreme adjustments in policy behavior, more incremental changes, and more adaptive behavior.

Studies of decision-making in U.S. Congressional committees highlight the role that diverse information sources play in problem definition. Committees consult interest groups and citizens, sometimes using field hearings to do so, when ascertaining the severity of a problem. Bureaucrats are involved in this process as well. Workman (2015: 51) notes the role bureaucratic expertise plays in problem definition when he claims that "Bureaucracies develop problem expertise associated with the monitoring of the policy environment, along with the more traditional solution expertise associated with policy implementation". The nature of problem search varies by issue. Shafran (2015) reports variation in the participation of bureaucrats and interest groups depending on the issue addressed. Workman, Shafran, and Bark (2017) show that as problem uncertainty increases, committees call more bureaucrats to testify. Moreover, committees have a tendency to call more careerist bureaucrats rather than political appointees as problem uncertainty increases.

While these studies do not focus on whether the reliance on sound policy information from experts on the nature of the problem space leads to less severe policy punctuations, they do show the general reliance of the U.S. legislative branch on a diversity of sources of information, including bureaucratic expertise. In recent times, Congress has moved from a more decentralized, committee-centered lawmaking system to a more party-centered top-down lawmaking system, implying larger policy punctuations as a consequence. It can be hoped that studies of these kinds of potential consequences will be examined in the future.

\section{Beyond Governments}

Do these factors that influence the adjustment patterns of governments also characterize broader systems of human organization? There is tantalizing evidence that they do. In a study of five general-purpose international organizations, Lundgren, Squatrito, and Tallberg (2017) found that the policy agendas of all displayed patterns of punctuated outputs, and the higher the institutional friction in the organization, the more subject to these punctuations the or- 
ganization was. Noting that the standard research approach to international organizations stresses resistance to change, the authors argue that, to the contrary, "Barriers to change do not only contribute to periods of stasis but also contribute to a build-up of pressure that generates disproportionate change when it eventually comes." (p.567).

In the U.S. context, it is common for politicians to call for the privatization of public endeavors under the assumption that government is inefficient and that the private sector can deliver the same services at lower costs. However, many of the components of friction that we have outlined as operating on governmental systems also apply to private firms. While incentive structures may differ, other components of friction are more immutable. Certainly, the information problem, with its roots in universal cognitive biases and limitations, is not likely to be overcome simply by changing venues from a public bureaucracy to a corporate one. Epp (2015) considers industries such as mail delivery and higher education, which see dual participation from public and private organizations. A comparison of budgetary changes reveals that the budgets of private firms are often more punctuated than those of government entities operating in the same industries. This suggests that firms are no better equipped to smoothly update policies in response to new information than are their government counterparts. A broader implication is that rather than relying on a false public vs. private dichotomy, we are better served by focusing directly on those elements that condition organizational responsiveness. In some cases, firms may operate with fewer frictions than governments, but the reverse is also possible.

\section{Concluding Comments}

While some degree of policy punctuation is necessary to overcome resistance and make required adjustments to changing circumstances, extreme patterns of punctuated policy changes are pathological. Disjointed and episodic extreme policy changes are indicators of a lack of continuous adaptive behavior.

Democracies have attributes that should lead to more adaptive policies than authoritarian systems, and, indeed, existing studies point to far more extreme policy instability in authoritarian systems than in democratic ones. Adaptive policies more closely address the problems facing a political system. So the more a policymaking system incorporates elements that encourage a focus on identifying and solving problems, the more adaptive and hence less punctuated policy will be.

But what attributes are most responsible for the volatility? We've focused on four basic factors critical in generating more extreme policy punctuations: friction imposed by formal rules and informal norms on the policymaking process, centralization in policymaking, lack of diversity in channels of information, and the absence of incentives to address problems. It is difficult to assess the relative importance of these factors because characteristics cluster in both authoritarian and democratic regimes. In authoritarian regimes, for example, centralization is generally associated with the suppression of information.

To try to separate out the effects of the four factors, we've examined the literature on variation within democracies because scholars have subjected these systems to more rigorous empirical study. This allows us to put forth several propositions linking institutions and practices to the tendency of systems to generate policy punctuations. We have varying degrees of confidence in them, but all are starting-points for understanding extreme policy volatility in policymaking systems. 


\section{Bibliography}

Baumgartner, F.R., Breunig, C., Green-Pedersen, C., Jones, B. D., Mortensen, P. B., Nuytemans, M., \& Walgrave, S. (2009). Punctuated Equilibrium in Comparative Perspective. American Journal of Political Science, 53(3), 603-620.

Baumgartner, F.R., Carammia, M., Epp, D. A., Noble, B., Rey, B., \& Yildirim, T. M. (2017). Budgetary Change in Authoritarian and Democratic Regimes. Journal of European Public Policy, 24(6), 792-808.

Baumgartner, F.R., \& Jones, B. D. (1991). Agenda Dynamics and Policy Subsystems. The journal of Politics, 53(4), 1044-1074.

Baumgartner, F. R., \& Jones, B. D. (2009). Agendas and Instability in American Politics. Chicago: University of Chicago Press.

Baumgartner, F.R., \& Jones, B. D. (2015). The Politics of Information: Problem Definition and the Course of Public Policy in America. Chicago: University of Chicago Press.

Bauer, R.A. (1966). Social Indicators. Cambridge, MA: The M.I.T. Press.

Bevan, S., \& Rasmussen, A. (2017). When Does Government Listen to the Public? Voluntary Associations and Dynamic Agenda Representation in the United States. Policy Studies Journal, 45, 1-22.

Bonafont, L.C., \& Palau, A. M. (2011). Assessing the Responsiveness of Spanish Policymakers to the Priorities of their Citizens. West European Politics, 34(4), 706-730.

Boswell, C. (2012). How Information Scarcity Influences the Policy Agenda: Evidence from UK Immigration Policy. Governance, 25(3), 367-389.

Boulding, K. E. (1966). The Ethics of Rational Decision. Management Science, 12(6), B-161.

Breunig, C. (2006). The More Things Change, the More Things Stay the Same: A Comparative Analysis of Budget Punctuations. Journal of European Public Policy, 13(7), 1069-1085.

Breunig, C., \& Jones, B.D. (2011). Stochastic Process Methods with an Application to Budgetary Data. Political Analysis, 19(1), 103-117.

Breunig, C., \& Koski, C. (2006). Punctuated Equilibria and Budgets in the American States. Policy Studies Journal, 34(3), 363-379.

Breunig, C., \& Koski, C. (2009). Punctuated Budgets and Governors' Institutional Powers. American Politics Research, 37(6), 1116-1138.

Breunig, C., \& Koski, C. (2012). The Tortoise or the Hare? Incrementalism, Punctuations, and their Consequences. Policy Studies Journal, 40(1), 45-68.

Breunig, C., \& Koski, C. (2018). Topping Off and Bottoming Out: Setting Budget Priorities Through Executive Power. Policy Studies Journal, 46.

Chan, K.N., \& Zhao, S. (2016). Punctuated Equilibrium and the Information Disadvantage of Authoritarianism: Evidence from the People's Republic of China. Policy Studies Journal, 44(2), 134-155.

Clarke, K. A., \& Stone, R. W. (2008). Democracy and the Logic of Political Survival. American Political Science Review, 102(3), 387-392.

Downs, A. (1972). Up and Down with Ecology: The Issue-Attention Cycle. The Public Interest, 28, 38-50.

Dreze, J \& Sen.A (1989). Hunger and Public Action. Oxford: Oxford University Press. 
Ebersole, P. (2015) \& Sen.A on Democracy and Famine. Phil Ebersole's Blog: Thoughts about Politics and the Passing Scene. https://philebersole.wordpress.com/2015/06/02/amartya-sen-on-democracy-and-famine/ Accessed 1/9/2019.

Epp, D.A. (2015). Punctuated Equilibria in the Private Sector and the Stability of Market Systems. Policy Studies Journal, 43(4),417-436.

Epp, D.A. 2018. The Structure of Policy Change. Chicago: University of Chicago Press.

Fagan, E. J., Jones, B. D., \& Wlezien, C. (2017). Representative systems and policy punctuations. Journal of European Public Policy, 24(6), 809-831.

Green-Pedersen, C., \& Mortensen, P. B. (2010). Who Sets the Agenda and who Responds to it in the Danish Parliament? A New Model of Issue Competition and Agenda-Setting. European Journal of Political Research, 49(2), 257-281.

Helliwell, J.F. (1994). Empirical Linkages Between Democracy and Economic Growth. British journal of political science, 24(2), 225-248.

Jones, B.D. (2016). A Radical Idea Tamed: the Work of Roger Cobb and Charles Elder. In Handbook of Public Policy Agenda Setting. Edward Elgar Publishing. 25-34.

Jones, B.D. (2001). Politics and the Architecture of Choice. Chicago: University of Chicago Press.

Jones, B.D \& Baumgartner F.R. (2005). The Politics of Attention. Chicago: University of Chicago Press.

Jones, B.D \& Baumgartner F.R. (2012). From There to Here: Punctuated Equilibrium to the General Punctuation Thesis to a Theory of Government Information Processing. Policy Studies Journal, 40, $1-18$.

Jones, B. D., Baumgartner, F. R., Breunig, C., Wlezien, C., Soroka, S., Foucault, M., ... \& Mortensen, P. B. (2009). A General Empirical Law of Public Budgets: A Comparative Analysis. American Journal of Political Science, 53(4), 855-873.

Jones, B. D., Larsen-Price, H., \& Wilkerson, J. (2009). Representation and American Governing Institutions. The Journal of Politics, 71(1), 277-290.

Jones, B. D., Thomas III, H. F., \& Wolfe, M. (2014). Policy Bubbles. Policy Studies Journal, 42(1), 146171.

Jones, B. D., Sulkin, T., \& Larsen, H. A. (2003). Policy Punctuations in American Political Institutions. American Political Science Review, 97(1), 151-169.

Jordan, M. M. (2003). Punctuations and Agendas: A New Look at Local Government Budget Expenditures. Journal of Policy Analysis and Management, 22(3), 345-360.

Kahnemann, D. (2011). Thinking Fast and Slow. New York: Farrar, Straus, and Giroux.

Karmakar, K. (2016). Essays in Fiscal Policy and Budgeting. Atlanta: PhD Dissertation, Department of Public Management and Public Policy, Georgia State University.

Lam, W. F., \& Chan, K. N. (2015). How Authoritarianism Intensifies Punctuated Equilibrium: The Dynamics of Policy Attention in Hong Kong. Governance, 28(4), 549-570.

Liu, Y. (2019). China's Entrepreneurs Wary of Its Future. New York Times (February 23: A1).

Lodge, M and Taber C.S. (2013). The Rationalizing Voter. New York: Cambridge University Press.

Lundgren, M., Squatrito, T., \& Tallberg, J. (2018). Stability and Change in International Policy-Making: A Punctuated Equilibrium Approach. The Review of International Organizations, 13(4), 547-572. 
Maor, M. (2012). Policy Overreaction, Journal of Public Policy, 32: 231-259

Maor, M. (2014). Policy Persistence, Risk Estimation and Policy Underreaction. Policy Sciences, 47(4), 425-443

Mortensen, P. (2009). Political Attention and Public Spending in the United States. Policy Studies Journal, 37, 435-455.

Page, S. E. (2008). The Difference. Princeton N.J.: Princeton University Press.

Pal, S. (2011). Media Freedom and Socio-Political Instability. Peace Economics, Peace Science and Public Policy, 17, 1554-8597.

Pritchett, L \& Summers L.H. (2014). Asiaphoria Meets Regression to the Mean. NBER Working Paper 20573. Cambridge MA: National Bureau of Economic Research.

Quinn, D. P., \& Woolley, J. T. (2001). Democracy and National Economic Performance: the Preference for Stability. American journal of political science, 634-657.

Reiter, D. (2017). Is Democracy a Cause of Peace? Oxford: Oxford Research Encyclopedias: Politics.

Robinson, S. E. (2004). Punctuated Equilibria, Bureaucratization, and School Budgets. Policy Studies Journal, 32(1), 25-40.

Robinson, S. E., \& Caver, F. S. R. (2006). Punctuated equilibrium and congressional budgeting. Political Research Quarterly, 59(1), 161-166.

Robinson, S. E., Caver, F. S., Meier, K. J., \& O’Toole Jr, L. J. (2007). Explaining policy punctuations: Bureaucratization and Budget Change. American Journal of Political Science, 51(1), 140-150.

Ryu, J.E. (2009). Exploring the Factors for Budget Stability and Punctuations: A Preliminary Analysis of State Government Sub-Functional Expenditures. Policy Studies Journal, 37, 457-473.

Sebok, M. (2019). The Comparative Agendas of Hybrid Regimes - A Research Agenda. Budapest: Hungarian Policy Agendas Project.

Sebok, M. \& Berki.T. (2018). Punctuated Equilibrium in Democracy and Autocracy: An Analysis of Hungarian Budgeting Between 1868-2013. European Political Science Review, 10(4), 589-611.

Seeberg, H.B. (2013). The Opposition's Policy Influence Through Issue Politicisation. Journal of Public Policy, 3, 89-10

Sen, A. (1981). Poverty and Famines. Oxford: Clarendon Press.

Shafran, J.B. (2015). Whirlpools of Information: Information Processing in Policy Subsystems 1995-2012. $\mathrm{PhD}$ Dissertation, Department of Government, University of Texas. Austin: University of Texas at Austin.

Sirimaneetham, V. (2006). Explaining Policy Volatility in Developing Countries. Discussion Paper No. 06.583 Bristol, UK: Department of Economics, Bristol University.

Siverson, R., Morrow, J.D., de Mesquita, B.B., \& Smith, A. (2003). The Logic of Political Survival. Cambridge: The MIT Press.

Soroka, S. N., \& Wlezien, C. (2015). The Majoritarian and Proportional Visions and Democratic Responsiveness. Electoral studies,40, 539-547.

Soroka, S. \& Wlezien.C. (2010). Degrees of Democracy: Politics, Public Opinion, and Policy. Cambridge: Cambridge University Press.

Tsebelis, G. (1995). Decision Making in Political Systems: Veto Players in Presidentialism, Parliamentarism, Multicameralism, and Multipartyism. British Journal of Political Science, 25, 289-325. 
Tsebelis, G. (1999). Veto Players and Law Production in Parliamentary Democracies: An Empirical Analysis. American Political Science Review, 93, 591-607.

True, J.L. (2000). Avalanches and Incrementalism. American Review of Public Administration, 30, 3-18.

Vliegenthart, R., \& Walgrave, S. (2011). Content Matters: The Dynamics of Parliamentary Questioning in Belgium and Denmark. Comparative Political Studies, 44(8), 1031-1059.

Williams, W. (1998). Honest Numbers and Democracy. Washington D.C.: Georgetown University Press.

Wlezien, C. and Soroka S.N. (2012). Political Institutions and the Opinion-Policy Link. West European Politics, 35, 1407-1432

Wlezien, C. and Soroka S.N. (2015). Electoral Systems and Opinion Representation. Representation, 51, 273-285.

Wolfe, M. (2012). Putting on the Brakes or Stepping on the Gas? Media Attention and the Speed of Policymaking. Policy Studies Journal, 40, 109-26.

Workman, S. (2015). The Dynamics of Bureaucracy in the U.S. Government. Cambridge: Cambridge University Press.

Workman, S., Shafran, J., \& Bark, T. (2017). Problem Definition and Information Provision by Federal Bureaucrats. Cognitive Systems Research,43, 140-152.

Worsham, J., \& Stores, C. (2012). Pet Sounds: Subsystems, Regimes, Policy Punctuations, and the Neglect of african american Farmers, 1935-2006. Policy Studies Journal, 40(1), 169-190. 